\title{
A Phase Ib/Il, open-label, multicenter study of INC280 (capmatinib) alone and in combination with buparlisib (BKM120) in adult patients with recurrent glioblastoma
}

\author{
Martin van den Bent ${ }^{1}$ (1) Analia Azaro ${ }^{2} \cdot$ Filip De Vos $^{3}$. Juan Sepulveda ${ }^{4}$ W. K. Alfred Yung ${ }^{5} \cdot$ Patrick Y. Wen $^{6}$. \\ Andrew B. Lassman ${ }^{7} \cdot$ Markus Joerger $^{8} \cdot$ Ghazaleh Tabatabai $^{9} \cdot$ Jordi Rodon $^{5} \cdot$ Ralph Tiedt $^{10} \cdot$ Sylvia Zhao $^{11}$. \\ Tiina Kirsilae $^{10} \cdot$ Yi Cheng $^{11} \cdot$ Sergio Vicente ${ }^{10} \cdot$ O. Alejandro Balbin ${ }^{12} \cdot$ Hefei Zhang ${ }^{11} \cdot$ Wolfgang Wick $^{13}$
}

Received: 10 September 2019 / Accepted: 9 November 2019 / Published online: 27 November 2019

(c) The Author(s) 2019

\begin{abstract}
Purpose To estimate the maximum tolerated dose (MTD) and/or identify the recommended Phase II dose (RP2D) for combined INC280 and buparlisib in patients with recurrent glioblastoma with homozygous phosphatase and tensin homolog (PTEN) deletion, mutation or protein loss.

Methods This multicenter, open-label, Phase Ib/II study included adult patients with glioblastoma with mesenchymal-epithelial transcription factor (c-Met) amplification. In Phase Ib, patients received INC280 as capsules or tablets in combination with buparlisib. In Phase II, patients received INC280 only. Response was assessed centrally using Response Assessment in Neuro-Oncology response criteria for high-grade gliomas. All adverse events (AEs) were recorded and graded.

Results 33 patients entered Phase Ib, 32 with altered PTEN. RP2D was not declared due to potential drug-drug interactions, which may have resulted in lack of efficacy; thus, Phase II, including 10 patients, was continued with INC280 monotherapy only. Best response was stable disease in $30 \%$ of patients. In the selected patient population, enrollment was halted due to limited activity with INC280 monotherapy. In Phase Ib, the most common treatment-related AEs were fatigue (36.4\%), nausea (30.3\%) and increased alanine aminotransferase (30.3\%). MTD was identified at INC280 Tab $300 \mathrm{mg}$ twice daily + buparlisib $80 \mathrm{mg}$ once daily. In Phase II, the most common AEs were headache (40.0\%), constipation (30.0\%), fatigue (30.0\%) and increased lipase (30.0\%).

Conclusion The combination of INC280/buparlisib resulted in no clear activity in patients with recurrent PTEN-deficient glioblastoma. More stringent molecular selection strategies might produce better outcomes.
\end{abstract}

Trial registration: NCT01870726.

Keywords Glioblastoma · INC280 · Capmatinib · Buparlisib · c-Met · PTEN

\section{Introduction}

Glioblastomas are the most common type of brain tumor and generally have a limited response to available therapies [1]. Even when optimally managed with combined chemo-irradiation, patients with glioblastomas have poor outcomes [2]

Electronic supplementary material The online version of this article (https://doi.org/10.1007/s11060-019-03337-2) contains supplementary material, which is available to authorized users.

Martin van den Bent

m.vandenbent@erasmusmc.nl

Extended author information available on the last page of the article with a median survival of 14-16 months in study cohorts. Available options for recurrent or progressive tumors are limited and novel therapeutic options are urgently needed. Glioblastoma growth is driven by aberrant activity of one or more signaling pathways. Dysregulation of the proto-oncogene MET (c-Met), and the phosphatidylinositol 3-kinase (PI3K) signaling pathways are frequent in glioblastoma $[3,4]$. Preclinical and translational studies have indicated that activation of MET and PI3K signaling are important in tumor initiation and maintenance [5]. Inhibition of MET can have potent anti-tumor effects, including regression of human glioblastoma tumor xenografts $[6,7]$. Loss of phosphatase and tensin homolog (PTEN), a negative regulator of PI3K, by mutation or gene deletion is the most common 
form of PI3K pathway dysregulation, occurring in around $25-44 \%$ of all glioblastomas [3, 8]. With complex genetic alterations in glioblastomas, blocking only one pathway may be insufficient to fully impede cancer cell growth, thus, combining therapies that strategically target multiple pathways may improve clinical outcomes in patients who fail first- or second-line treatment for recurrent glioblastoma.

In preclinical models, buparlisib (BKM120), a PI3K inhibitor, has been combined with INC280 (capmatinib), a MET inhibitor, and synergy between the two agents has been observed in PTEN-null glioblastoma cell lines that express hepatocyte growth factor (HGF; data not shown). In addition, in an in vivo model of a human glioblastoma xenograft with a PTEN mutation and HGF expression (presumably leading to autocrine MET activation), the combination of these two agents was significantly more efficacious than either agent alone (Supplemental Fig. 1). INC280 has also demonstrated preclinical and clinical activity in tumors with MET dysregulation [9-12]. Buparlisib has demonstrated activity in tumors with PI3K activation [13-15].

Here we report results from a multicenter, open-label, Phase Ib/II study. The aim of the Phase Ib part was to estimate the maximum tolerated dose (MTD) and/or to identify the recommended Phase II dose (RP2D) for the combination of INC280 and buparlisib, followed by the Phase II part to assess the clinical efficacy of INC280 as a single agent and in combination with buparlisib, and to further assess the safety.

In addition, a surgical arm (which comprised patients that were candidates for surgical resection) was planned to determine the pharmacokinetic/pharmacodynamic (PK/PD) profile of the study drug combination in patients undergoing tumor resection for recurrent glioblastoma after 7 to 10 days of treatment. Because the RP2D for the combination was not declared, the Phase II was conducted with INC280 monotherapy only.

\section{Materials and methods}

\section{Study design and conduct}

For the Phase Ib part, adults ( $\geq 18$ years) with recurrent glioblastoma and documented homozygous PTEN deletion, PTEN mutation or protein loss assessed with immunohistochemistry (IHC) for PTEN (H score $<10)$ were eligible for enrollment in this study, which was confirmed by local documentation or central assessment. For the Phase II part, patients were pre-screened for MET verified centrally by fluorescence in situ hybridization (FISH) first and, if the gene copy number (GCN) was $>5$, were allocated to the INC280 single agent arm. Patients with tumours harbouring fusion transcripts or mutant MET were eligible after documented agreement with the sponsor. Patients with GCN $\leq 5$ were pre-screened for PTEN and were planned to be allocated to the combination arm of INC280 with buparlisib (although this arm was never activated; Supplemental Fig. 2).

Phase I single agent trials have determined the MTD and RP2D of buparlisib to be $100 \mathrm{mg} /$ day [16, 17]. Additional key inclusion criteria were Eastern Cooperative Oncology Group performance status (ECOG PS) $\leq 2$; histologically confirmed glioblastoma regardless of IDH status, radiologically proven relapse according to the Response Assessment in Neuro-Oncology (RANO) criteria [18], $\leq 2$ prior systemic therapies; prior treatment with vascular endothelial growth factor (VEGF) directed therapy was allowed. Key exclusion criteria included pregnancy, prior/current treatment with MET inhibitor or HGF-targeted therapy, prior/current PI3K inhibitors, or mammalian target of rapamycin (mTOR) inhibitors, active cardiac disease or other cardiac abnormalities, gastrointestinal disease or impairment that could significantly alter drug absorption, and history of psychological impairment.

In the Phase Ib part, patients were enrolled into one of six dosing cohorts based on human safety, PK and preclinical PK-efficacy data to receive INC280 as either oral capsules (Cap) or tablets (Tab). The film-coated Tab formulation was developed to improve patient convenience and consequently, compliance. The Tab formulation provides higher exposure than the Cap; the Tab dose was calculated to achieve a comparable exposure rate to the INC280 Cap. Dose escalation of the combination treatment was guided by a Bayesian logistic regression model (BLRM) in order to monitor patient safety. The switch from INC280 Cap to Tab occurred at the start of cohort 5 .

The protocol was amended during Phase Ib to allow for a change in local pre-screening to be performed during the dose escalation; a threshold for PTEN negativity of an $\mathrm{H}$ score $<10$ for PTEN IHC was introduced to align with the threshold currently used by the central laboratory that was based on the medical literature [19].

All patients in Phase II received INC280 monotherapy over a 28-day cycle. Treatment continued until unacceptable toxicity, disease progression or discontinuation at the discretion of the Investigator, or by withdrawal of patient consent. Dose adjustments were permitted to manage treatment-related toxicities.

A protocol amendment was also made during Phase II of the study in which an INC280-monotherapy arm was introduced to investigate single-agent INC280 in glioblastoma patients with altered MET (amplified GCN $>5$, fusion or mutant). The inclusion criterion was modified to add 'MET amplification by FISH (fusion transcripts or mutant MET may be eligible after discussion with the sponsor)'. 


\section{Primary objectives}

The primary objective of Phase Ib was to establish the MTD and to identify the RP2D for the combination of INC280 and buparlisib. The primary objective of Phase II was to assess the clinical efficacy and safety of INC280 alone and in combination with buparlisib; and for the surgical arm, the objective was to determine the PK/PD characteristics of the combination of INC280 and buparlisib. This analysis was not performed, as the Phase II part was limited to INC280 monotherapy in MET-amplified glioblastoma based on PK findings of Phase Ib.

\section{Assessments}

Tumor response and progression was assessed using the RANO Working Group response criteria for high-grade gliomas [18]. The radiological evaluation was reviewed centrally. Magnetic resonance imaging and clinical presentation were evaluated at baseline and repeated at 8-week intervals during the study until disease progression, the start of another antineoplastic treatment, or death.

All adverse events (AEs) were recorded and graded according to the Common Terminology Criteria for AEs (CTCAE) version 4.03 at every visit. AE monitoring continued for at least 30 days following the last dose of study treatment. Complete physical examinations and assessment of vital signs were performed on scheduled days. When dose-limiting toxicity (DLT) occurred, study treatment was interrupted and the toxicity was managed according to prespecified criteria. Blood samples were collected for INC280 and buparlisib PK analysis.

\section{Results}

\section{Patient characteristics}

\section{Patient demographics and baseline characteristics}

In Phase $\mathrm{Ib}$, patients $(\mathrm{n}=33)$ were primarily male $(72.7 \%)$, Caucasian $(87.9 \%$ ), with a median age of 59.0 years (Table 1). All except one patient had altered PTEN (deletion, mutation or protein loss). One patient had PTEN-positive IHC and no PI3K mutations, but was included based on detection of MET amplification by the investigator's institution. Patients were entered into one of the following dose cohorts: INC280 Cap 200, 400, or $500 \mathrm{mg}$ twice daily (BID) + $50 \mathrm{mg}$ buparlisib once daily (QD); INC280 Cap $500 \mathrm{mg}$ BID + $80 \mathrm{mg}$ buparlisib QD; or INC280 Tab 300 or $400 \mathrm{mg}$ BID $+80 \mathrm{mg}$ buparlisib QD.

Ten patients entered the INC280 monotherapy arm (Phase II) (median age 48 years; 70\% women, 90\% Caucasian;
Table 1 Patient demographics and baseline characteristics

\begin{tabular}{lll}
\hline Characteristic & $\begin{array}{l}\text { Phase Ib } \\
\text { INC280+ buparlisib } \\
\text { (all patients) }\end{array}$ & $\begin{array}{l}\text { Phase II INC280 } \\
400 \mathrm{mg} \text { BID Tab }\end{array}$ \\
\hline $\mathrm{N}$ & 33 & 10 \\
Median age, years (range) & $59.0(27-75)$ & $48.0(32-63)$ \\
Sex: male, n (\%) & $24(72.7)$ & $3(30.0)$ \\
Race, n (\%) & & \\
Black & $1(3.0)$ & 0 \\
Caucasian & $29(87.9)$ & $9(90.0)$ \\
Other & $3(9.1)$ & 0 \\
Unknown & 0 & $1(10.0)$ \\
ECOG PS, n (\%) & & $3(30.0)$ \\
0 & $13(39.4)$ & $5(50.0)$ \\
1 & $18(54.5)$ & $2(20.0)$ \\
2 & $2(6.1)$ & $7(70.0)$ \\
Type of last antineoplastic therapy, n (\%) & $1(10.0)$ \\
Medication & $27(81.8)$ & $2(20.0)$ \\
Radiotherapy & $1(3.0)$ & \\
Surgery & $5(15.2)$ & \\
\hline
\end{tabular}

Table 1). From 1st June 2015, 148 patients were screened for entry into the Phase II of this study; 10 patients (6.76\%) were treated.

\section{Biomarkers}

In Phase II, patients had a range of MET gene copy number and co-occurring genetic alterations assessed by next generation sequencing (NGS using the Foundation Medicine T7 panel; summarized in Table 2). Further analysis of MET copy number status by NGS in 9 of the 10 Phase II patients revealed that $7 / 9$ showed broad copy number gain of a chromosomal region containing the MET gene, with copy numbers in the range of 4 to 6. Only 2/9 tumors (Patients 002 and 004) showed evidence for focal amplification of the MET gene, with copy number $\geq 9$. In line with these observations, the two tumors with focal MET amplification displayed a MET:CEP-7 ratio in the FISH assay of around 5. This ratio was lower (average $~ 1.7$ ) in the 7 tumors with broad copy number gain, with the exception of one tumor (Patient 010) with a marked discrepancy between copy number by FISH and NGS ( 20 vs. 4 without any evidence of focality in either case). Despite the selection of MET FISH copy number $\geq 5$, MET protein expression, as assessed by IHC, was relatively low across tumor samples (Fig. 1). The range of MET gene copy numbers and genetic alterations in the Phase $\mathrm{Ib}$ is shown in Table 3. 
Table 2 NGS data with potential (known or likely) functional significance (Phase II data)

\begin{tabular}{|c|c|c|c|c|c|c|c|c|c|}
\hline \multirow[t]{2}{*}{ Patient ID } & \multirow{2}{*}{$\begin{array}{l}\text { Best } \\
\text { overall } \\
\text { response }\end{array}$} & \multirow[t]{2}{*}{ IHC } & \multicolumn{2}{|l|}{ FISH } & \multicolumn{2}{|l|}{ FM NGS } & \multicolumn{3}{|c|}{ Sequencing data with potential (known or likely) functional significance } \\
\hline & & & $\begin{array}{l}\text { MET } \\
\text { copy } \\
\text { number }\end{array}$ & Ratio $^{\mathrm{b}}$ & $\begin{array}{l}\text { MET } \\
\text { Copy } \\
\text { Number }\end{array}$ & Ratio $^{c}$ & $\begin{array}{l}\text { Copy number variant } \\
\text { (copy number) }\end{array}$ & Short variant & rearrangement \\
\hline 001 & PD & 32 & 5.59 & 1.19 & 5 & 612.1 & $\begin{array}{l}\text { KDR(13), KIT(13), } \\
\text { PDGFRA(13) }\end{array}$ & $\begin{array}{l}\text { ATRX, EPHA6, H3F3A, } \\
\text { HSP90AA1, TP53 }\end{array}$ & $\mathrm{N} / \mathrm{F}$ \\
\hline 002 & SD & 40 & 11.63 & 4.86 & $\begin{array}{l}9 \\
14^{\mathrm{d}}\end{array}$ & $\begin{array}{l}1.0 \\
0.4^{\mathrm{d}}\end{array}$ & $\begin{array}{l}\text { CDK4(95), IGF1R(10), } \\
\text { MET(9) }\end{array}$ & ATRX, IDH1, TP53 & $\mathrm{N} / \mathrm{F}$ \\
\hline 003 & PD & 117 & 6.56 & 2.51 & 5 & 154.1 & $\begin{array}{l}\text { CDK4(63),GLI1(22), } \\
\text { MYCN(35), TP53(0) }\end{array}$ & ATRX, IDH1 & $\mathrm{N} / \mathrm{F}$ \\
\hline 004 & PD & 100 & 12.62 & 5.21 & 16 & 1.5 & $\begin{array}{l}\text { CDKN2A(0), } \\
\text { CDKN2B(0), } \\
\text { MET(18) }\end{array}$ & $\begin{array}{l}\text { AR, NF1, NPM1, PIK3R1, } \\
\text { PRDM1 }\end{array}$ & $\mathrm{N} / \mathrm{F}$ \\
\hline 005 & PD & 5 & 5.12 & 1.26 & 3 & 1258.1 & & PTEN, TERT, TP53 & KEAP1 \\
\hline 006 & PD & 112 & 6.38 & 1.85 & $\begin{array}{l}6 \\
6^{\mathrm{d}}\end{array}$ & $\begin{array}{l}63.5 \\
29.4^{\mathrm{d}}\end{array}$ & $\begin{array}{l}\text { KDR(10), KIT(11), } \\
\text { PDGFRA(40), } \\
\text { TP53(0) }\end{array}$ & $\begin{array}{l}\text { CDKN2A, FANCL, LZTR1, } \\
\text { PIK3CA, TERT }\end{array}$ & PDGFRA \\
\hline 007 & SD & 0 & 8 & 1.41 & 4 & 396.3 & EGFR(107) & ARAF, BCL2, CDKN2A & EGFR \\
\hline 008 & $\mathrm{UNK}^{\mathrm{a}}$ & 3 & 7.84 & 3.27 & N/A & N/A & & EGFR, NF1, PTEN & $N / F$ \\
\hline 009 & SD & 0 & 5.12 & 1.08 & 6 & 1258.1 & CDK4(29) & KMT2C, NF1, TERT, TP53 & $\mathrm{N} / \mathrm{F}$ \\
\hline 010 & PD & 33 & $20^{\mathrm{e}}$ & 2.5 & 4 & 1205.6 & $\mathrm{~N} / \mathrm{F}$ & $\begin{array}{l}\text { APC, ATRX, NF1, PTEN, RB1, } \\
\text { TP53 }\end{array}$ & FAT1 \\
\hline
\end{tabular}

$F I S H$ fluorescent in situ hybridization (for MET gene copy number in the nuclei), $F M$ foundation medicine, $I D$ patient identification number, $I H C$ immunohistochemical staining score, $\mathrm{H}$ score (of MET protein expression at the plasma membrane or in the cytoplasm), N/A not applicable, $N / F$ no findings, $P D$ progressive disease, $S D$ stable disease, $U N K$ unknown

${ }^{a}$ Clinical PD, the lesions were not assessed

${ }^{b}$ Ratio of MET copies to CEP7 copies

${ }^{c}$ Ratio of the size of genomic fragment overlapping with MET relative to the size of the MET gene

${ }^{\mathrm{d}}$ Two different segments overlapping the MET gene were called by the analysis pipeline downstream of the hybridization capture and NGS process [31]

${ }^{\mathrm{e}}$ Note discrepancy and high copy number by FISH which does not correlate with NGS data and may represent a potential technical issue with FISH

\section{Safety}

\section{Phase lb dose escalation}

All 33 patients in Phase Ib discontinued study treatment and reported at least one AE. The main reason for study discontinuation was disease progression $(n=29,87.9 \%)$; other reasons were AEs $(n=2)$ and consent withdrawal/patient decision $(n=2)$. Treatment-related AEs were reported in $84.8 \%$ of the Phase Ib patients. The most commonly reported treatment-related AEs were fatigue (36.4\%), nausea $(30.3 \%)$, alanine aminotransferase increased (30.3\%), aspartate aminotransferase increased (24.2\%), depression (24.2\%) and hyperglycemia (21.2\%). Grade $\geq 3$ AEs were reported in 24 patients (72.7\%). Treatment-related grade $\geq 3$ AEs were reported in 12 patients (36.4\%). MTD was identified at INC280 Tab $300 \mathrm{mg}$ BID + buparlisib $80 \mathrm{mg}$ QD, a dosage received by 7 patients. DLT was observed in four patients: nausea (INC280 Tab $300 \mathrm{mg}$ BID + buparlisib
$80 \mathrm{mg}$ QD; grade 3), personality change (INC280 Cap $400 \mathrm{mg}$ BID + buparlisib $50 \mathrm{mg}$ QD; grade 3), and elevated transaminases in two patients (both INC280 Tab $400 \mathrm{mg}$ BID+ buparlisib $80 \mathrm{mg}$ QD; grade 3; Table 4).

\section{Phase II}

As in Phase Ib, all patients in Phase II reported at least one AE. Treatment-related AEs were reported in $60.0 \%$ of the Phase II patients. The most commonly reported AEs by preferred term were headache $(40.0 \%)$, constipation $(30.0 \%)$, fatigue (30.0\%) and increased lipase (30.0\%). Grade $\geq 3$ AEs were reported in nine patients $(90.0 \%)$. Treatment-related grade $\geq 3$ AEs were reported two patients $(20.0 \%)$.

In terms of exposure to INC280, the average mean daily dose ( \pm standard deviation, SD) for all patients in the Phase II part of this study was $754.1 \mathrm{mg}( \pm 125.21)$, with a cumulative dose of $54,220.0 \mathrm{mg}( \pm 43,045.24)$. 


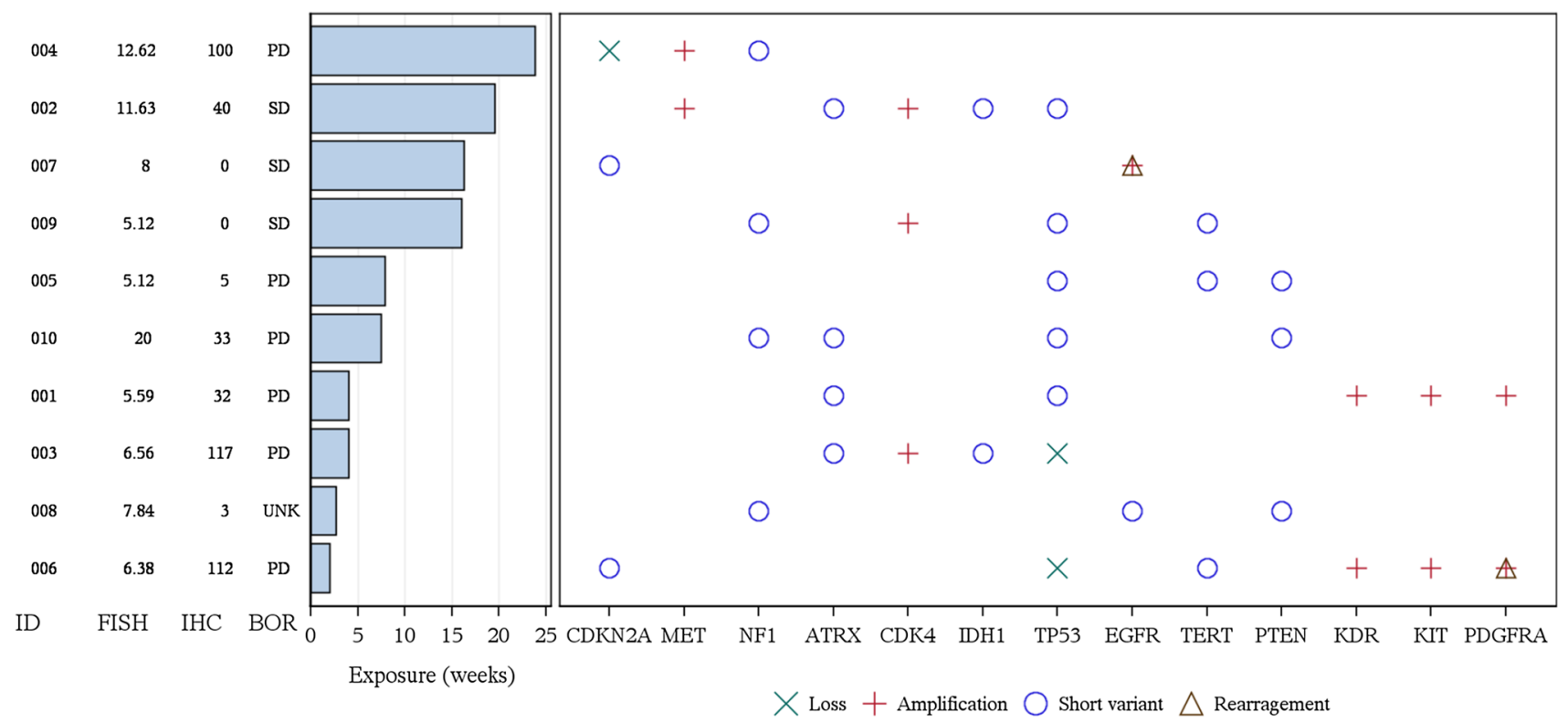

Fig. 1 Most frequent somatic genetic alterations observed in tumor samples with known/likely functional significance using Next Generation Sequencing analysis and duration of exposure. Phase II subjects only; two (or more) alterations were observed with known/likely functional significance; ATRX, ATP-dependent helicase ATRX, BOR best overall response, $C D K 4$ cyclin dependent kinase $4, C D K N 2 A$ cyclin-dependent kinase inhibitor 2A, EGFR epidermal growth factor receptor, FISH fluorescent in situ hybridization (for MET gene copy number in the nuclei), $I D$ patient identification number, $I D H I$

\section{Pharmacokinetics}

During Phase Ib, the target exposures for both drugs in the combination therapy were not met in the combination treatment arm. Compared with data from single-agent treatment studies, the exposures of INC280 and buparlisib were significantly lower when dosed in combination (Table 5). Compared with single-agent INC280 (CINC280A2201, data on file), the area under the curve (AUC) of INC280 $400 \mathrm{mg}$ BID in combination with buparlisib $80 \mathrm{mg}$ QID was 0.73 -fold. Compared with single-agent buparlisib [17], the AUC of buparlisib $80 \mathrm{mg}$ QD in combination with INC280 $400 \mathrm{mg}$ BID was 0.38 -fold. The mechanism for this reduced exposure is not known at present but the possibility of drug-drug interaction cannot be ignored. AUCs and other pharmacokinetic parameters are presented in Table 5.

\section{Efficacy}

\section{Overall efficacy}

The combination of INC280 + buparlisib demonstrated very limited activity in these 33 patients with PTEN-altered glioblastoma. RP2D was not declared due to potential drug-drug interactions and hence a low drug exposure, which may have isocitrate dehydrogenase $1, I H C$ immunohistochemical staining score (of MET protein expression at the plasma membrane or in the cytoplasm), KDR kinase insert domain receptor, $K I T$ receptor tyrosine kinase protein KIT, $M E T$ tyrosine-protein kinase MET, $N F 1$ neurofibromatosis type $1, P D$ progressive disease, $P D G F R A$ platelet-derived growth factor receptor alpha, PTEN phosphatase and tensin homolog, TERT telomerase reverse transcriptase, $S D$ stable disease, TP53, tumor protein $\mathrm{p} 53, \mathrm{UNK}$ unknown

resulted in lack of observed efficacy with the INC280 and buparlisib drug combination in Phase Ib. Consequently, the combination arms planned for Phase II were not initiated.

In the Phase II INC280 monotherapy arm, 10 patients were enrolled. No patient achieved partial (PR) or complete response (CR). Best response of stable disease (SD) was observed in 3 of 10 patients $(30.0 \%)$ in Phase II, and lasted between 16-20 weeks from the start of treatment until disease progression, similar to the exposure time (Fig. 1). Due to the limited activity observed with INC280 monotherapy (400 mg BID Tab) in this population of patients with recurrent glioblastoma, the enrollment of patients was halted early after pre-planned futility analysis and the primary endpoint, progression-free survival rate at 6 months, was not assessed due to insufficient sample size.

\section{Efficacy according to biomarkers}

All alterations identified and key co-occurring genetic alterations as identified by NGS are shown in Table 2. Alterations in several genes previously linked to glioblastoma (e.g. PTEN, TP53, EGFR) [3] were detected, along with other mutations of unknown significance. 
Table 3 NGS data with potential (known or likely) functional significance (Phase Ib data)

\begin{tabular}{|c|c|c|c|c|c|}
\hline \multirow[t]{2}{*}{ Patient ID } & \multirow{2}{*}{$\begin{array}{l}\text { Best } \\
\text { overall } \\
\text { response }\end{array}$} & \multirow[t]{2}{*}{ IHC } & \multicolumn{3}{|c|}{ Sequencing data with potential (known or likely) functional significance } \\
\hline & & & Copy number variant (copy number) & Short variant & Rearrangement \\
\hline 101 & PD & 0 & & & \\
\hline 102 & PD & 50 & $\begin{array}{l}\text { CDK4 (78), GLI1 (18), MDM2 (70), SOX2 } \\
\text { (7) }\end{array}$ & PTEN, TERT & \\
\hline 103 & PD & & CDK4 (36), MDM2 (65) & PTEN, TERT & \\
\hline 104 & PD & 80 & CDKN2A (0), CDKN2B (0), EGFR (128) & AXL, EGFR, FLT4, KDM5A, TERT & \\
\hline 105 & PD & 90 & EGFR (61), ERRFI1 (0) & EGFR, PTEN, TERT & CDKN2A, EGFR \\
\hline 106 & PD & 100 & & & \\
\hline 107 & $\mathrm{PD}$ & & & ARID1A, FGFR2, PTEN, STAG2 & \\
\hline 108 & PD & & CDKN2A (0), CDKN2B (0), EGFR (110) & $\begin{array}{l}\text { EGFR, FAT1, NOTCH1, PTEN, SPTA1, } \\
\text { TERT }\end{array}$ & EGFR \\
\hline 109 & PD & 101 & CDKN2A (0), CDKN2B (0) & FGFR4, NF1, PTEN, RB1, TERT, TP53 & NF1 \\
\hline 110 & PD & 100 & CDKN2A (0), CDKN2B (0), EGFR (59) & EGFR, PTEN, TERT & \\
\hline 111 & $\mathrm{PD}$ & & $\begin{array}{l}\text { CDKN2A (0), CDKN2B (0), EGFR (46), } \\
\text { MDM4 (28), PIK3C2B (30) }\end{array}$ & EGFR, PTEN, TERT & EGFR \\
\hline 112 & PD & 90 & RB1 (0) & NF1, PTEN, TERT & \\
\hline 113 & PD & 50 & $\begin{array}{l}\text { CDKN2A (0), CDKN2B (0), MDM4 (53), } \\
\text { PIK3C2B (54) }\end{array}$ & BRCA2, PTEN, STAG2, TERT & EGFR \\
\hline 114 & UNK & 80 & CDKN2A (0), CDKN2B (0), EGFR (40) & PTEN, TERT & \\
\hline 115 & PD & & CDKN2A (0) & PTEN & \\
\hline 116 & $\mathrm{PD}$ & 100 & $\begin{array}{l}\text { CDKN2A (0), CDKN2C (0), KDR (6), KIT } \\
\text { (6), PDGFRA (6), PTEN (0) }\end{array}$ & TERT, TP53 & \\
\hline 117 & PD & 110 & & NF1, PIK3CA, PTEN, RB1, TP53 & \\
\hline 118 & PD & & TP53 (0) & PTEN, TERT & \\
\hline 119 & PD & 0 & CDKN2A (0), CDKN2B (0), EGFR (60) & TERT & \\
\hline 120 & $\mathrm{PD}$ & 0 & $\begin{array}{l}\text { CCND2 (45), CDK4 (47), EGFR (16), FGF23 } \\
\text { (10), FGF6 (10), FRS2 (102), MDM2 (93) }\end{array}$ & PTEN, TERT & \\
\hline 121 & PD & 0 & CDKN2A (0), CDKN2B (0), EGFR (45) & LRP1B, PTEN, TERT & EGFR \\
\hline 122 & PD & 55 & & & \\
\hline 123 & PD & 80 & CDKN2A (0), CDKN2B (0), EGFR (92) & EGFR, TERT & EGFR \\
\hline 124 & $\mathrm{PD}$ & 100 & CDKN2A (0), CDKN2B (0) & PTEN, STAG2, TERT & \\
\hline 125 & PD & 30 & & STK11, TERT & \\
\hline 126 & PD & & & & \\
\hline 127 & PD & 65 & & PTEN, TERT & \\
\hline 128 & $\mathrm{SD}^{*}$ & 100 & CDK4 (61), KIT (6), PDGFRA (6) & TP53 & \\
\hline 129 & PD & 100 & CDKN2A (0), CDKN2B (0), EGFR (125) & EGFR & EGFR \\
\hline 130 & UNK & & & & \\
\hline 131 & PD & 90 & CDKN2A (0) & $\mathrm{BCOR}$ & \\
\hline 132 & PD & 100 & CDKN2A (0), CDKN2B (0), EGFR (72) & EGFR, GLI1, PTEN, TERT & \\
\hline 133 & UNK & 0 & $\begin{array}{l}\text { CDKN2A (0), CDKN2B (0), EGFR (42), } \\
\text { JUN (9), PTEN (0) }\end{array}$ & EGFR, TERT & EGFR \\
\hline
\end{tabular}

FISH fluorescent in situ hybridization (for MET gene copy number in the nuclei), $F M$ foundation medicine, $I D$ patient identification number, $I H C$ immunohistochemical staining score, $\mathrm{H}$ score (of MET protein expression at the plasma membrane or in the cytoplasm), $P D$ progressive disease, $S D$ stable disease, $U N K$ unknown

${ }^{\mathrm{a}}$ Clinical PD, the lesions were not assessed

${ }^{b}$ Ratio of MET copies to CEP7 copies

${ }^{\mathrm{c}}$ Ratio of the size of genomic fragment overlapping with MET relative to the size of the MET gene

${ }^{\mathrm{d}}$ Note discrepancy and high copy number by FISH which does not correlate with NGS data and may represent a potential technical issue with FISH

*Patient achieved stable disease (SD) at Cycle 1, Day 15; by Day 27 of Cycle 1, this patient was assessed to have progressive disease (PD) 
Table 4 Dose-limiting toxicities by dose

\begin{tabular}{lllll}
\hline Cohort & $\begin{array}{l}\text { Total daily doses INC280 } \\
\text { (BID) + buparlisib (QD) }\end{array}$ & $\begin{array}{l}\text { No. of patients } \\
\text { treated }\end{array}$ & $\begin{array}{l}\text { No. of patients in the dose- } \\
\text { determining set }\end{array}$ & $\begin{array}{l}\text { No. of DLTs } \\
\text { in cycle 1 }\end{array}$ \\
\hline \multicolumn{2}{l}{ INC280 capsule formulation } & & & 0 \\
1 & $200 \mathrm{mg}+50 \mathrm{mg}$ & 5 & 4 & 1 \\
2 & $400 \mathrm{mg}+50 \mathrm{mg}$ & 6 & 5 & 0 \\
3 & $500 \mathrm{mg}+50 \mathrm{mg}$ & 4 & 3 & 0 \\
4 & $500 \mathrm{mg}+80 \mathrm{mg}$ & 6 & 4 & 1 \\
INC280 tablet formulation & & & 2 \\
5 & $300 \mathrm{mg}+80 \mathrm{mg}$ & 7 & 7 & 4 \\
6 & $400 \mathrm{mg}+80 \mathrm{mg}$ & 5 & 4 & \\
\hline
\end{tabular}

$B I D$ twice daily, $D L T$ dose limiting toxicity, $Q D$ once a day

Table 5 Primary pharmacokinetic parameters for INC280 and for buparlisib (Phase 1b data)

\begin{tabular}{|c|c|c|c|c|c|c|}
\hline Cycle 1, Day 15 & $\begin{array}{l}\text { INC } 200 \mathrm{mg} \text { Cap } \\
\text { BID + bup } 50 \mathrm{mg} \\
\text { QD }\end{array}$ & $\begin{array}{l}\text { INC } 400 \mathrm{mg} \text { Cap } \\
\text { BID + bup } 50 \mathrm{mg} \\
\text { QD }\end{array}$ & $\begin{array}{l}\text { INC } 500 \mathrm{mg} \text { Cap } \\
\text { BID + bup } 50 \mathrm{mg} \\
\text { QD }\end{array}$ & $\begin{array}{l}\text { INC } 500 \mathrm{mg} \text { Cap } \\
\text { BID + bup } 80 \mathrm{mg} \\
\text { QD }\end{array}$ & $\begin{array}{l}\text { INC } 300 \mathrm{mg} \mathrm{Tab} \\
\text { BID + bup } 80 \mathrm{mg} \\
\text { QD }\end{array}$ & $\begin{array}{l}\text { INC } 400 \mathrm{mg} \mathrm{Tab} \\
\text { BID + bup } 80 \mathrm{mg} \\
\text { QD }\end{array}$ \\
\hline \multicolumn{7}{|l|}{ INC280 } \\
\hline $\mathrm{N}$ & 5 & 4 & 3 & 2 & 3 & 4 \\
\hline $\begin{array}{l}\mathrm{AUC}_{\mathrm{tau}}(\mathrm{h} * \mathrm{ng} / \\
\mathrm{mL})\end{array}$ & 6260 & 8580 & 12,800 & 2650 & 12,200 & 15,300 \\
\hline $\begin{array}{l}\text { Geo-mean (Geo- } \\
\text { CV\%) }\end{array}$ & $(45)$ & (79) & (99) & (46) & (33) & (19) \\
\hline $\mathrm{C}_{\max }(\mathrm{ng} / \mathrm{mL})$ & 1350 & 1850 & 3400 & 494 & 3460 & 3870 \\
\hline $\begin{array}{l}\text { Geo-mean (Geo- } \\
\text { CV\%) }\end{array}$ & (59) & (78) & (114) & (71) & (39) & $(55)$ \\
\hline \multicolumn{7}{|l|}{ Buparlisib } \\
\hline $\mathrm{N}$ & 5 & 5 & 3 & 2 & 4 & 4 \\
\hline $\begin{array}{l}\mathrm{AUC}_{\mathrm{tau}}(\mathrm{h} * \mathrm{ng} / \\
\mathrm{mL})\end{array}$ & 8210 & 5190 & 6270 & 10,047 & 9950 & 7180 \\
\hline $\begin{array}{l}\text { Geo-mean (Geo- } \\
\text { CV\%) }\end{array}$ & (33) & $(50)$ & (18) & (61) & (13) & (39) \\
\hline $\mathrm{N}$ & 5 & 5 & 3 & 2 & 5 & 4 \\
\hline $\mathrm{C}_{\max }(\mathrm{ng} / \mathrm{mL})$ & 680 & 429 & 580 & 779 & 853 & 799 \\
\hline $\begin{array}{l}\text { Geo-mean (Geo- } \\
\text { CV\%) }\end{array}$ & (13) & (38) & (29) & (19) & (28) & (67) \\
\hline
\end{tabular}

Geometric mean AUCtau, ss of INC280 tablet $400 \mathrm{mg}$ bid is $21,000 \mathrm{ng} * \mathrm{hr} / \mathrm{mL}$ in monotherapy (INC280 IB v6);

Geometric mean AUCtau, ss of buparlisib $80 \mathrm{mg}$ qd is $19,100 \mathrm{ng} * \mathrm{hr} / \mathrm{mL}$ in monotherapy (BKM120 IB v10)

Vertical, heavy line indicates the INC280 Cap vs Tab treatments

$A U C$ area under the curve, BID twice daily, bup buparlisib, cap capsule, Cmax maximum (peak) observed drug concentration, INC INC280, $Q D$ once daily, $t a b$ tablet

\section{Discussion}

This study was initially based on the hypothesis that INC280 and buparlisib would have a synergistic antitumor activity in recurrent glioblastoma with concomitant MET and PI3K activation. The safety profile of the combination of INC280 and buparlisib was consistent with the known safety profile of these agents as monotherapies in the oncology setting $[10,11,20-22]$ No new safety signals were identified. One patient experienced a personality change, which is consistent with the know safety profile of buparlisib [20]. RP2D was not declared due to a lack of efficacy in the drug combination, low drug exposure and potential drug-drug interactions in the Phase $\mathrm{Ib}$ stage of this trial.

During the conduct of this trial, INC280 film-coated Tabs were introduced into the study to improve patient convenience, based on a relative bioavailability study (data 
on file) in which INC280 Tabs were shown to provide higher drug exposure than Caps.

Originally, it was not thought that INC280 or buparlisib would have sufficient single-agent activity to block cancer cell growth due to the complex genetic alterations in glioblastoma. However, while Phase Ib of this trial was in progress, INC280 showed preliminary efficacy signals in two patients with MET amplified recurrent glioblastoma in other trials (unpublished data on file and a patient receiving compassionate use of INC280 + inhibitor LDE225). Additionally, INC280 has shown promising clinical efficacy in non-small-cell lung carcinoma with MET amplification [10]. Based on this emerging clinical evidence, the decision was made to continue with a monotherapy arm only in Phase II to investigate single-agent INC280 in MET amplified glioblastoma patients. For this part of the study, patients were enrolled if their tumors showed a relative MET copy number of $\geq 5$, as measured using a FISH assay.

No evidence of activity was observed with INC280 monotherapy in Phase II. However, the majority of Phase II patients had tumors with elevated MET copy number in the context of broad gain of chromosome 7. In addition, MET protein expression in those tumor samples, as measured by IHC, was relatively low despite increased MET gene copy numbers (Table 2).

The discrepancy between MET copy number (FISH) and protein expression (IHC) is one that requires careful consideration and highlights the challenges of defining molecular inclusion criteria for clinical trials. Given the small sample size it is difficult to determine the cause of the apparent discrepancy between gene copy number and protein expression. Several possible explanations exist. Sample age may have played a role in the low IHC results as all samples were from archival material (mean [SD] sample age for Phase II of 514 [ \pm 359$]$ days). Discordance between FISH and IHC has been described before for other cancers [23-26]. Moreover, simple chromosome polysomy does not necessarily lead to increased transcription.

Significant heterogeneity regarding co-occurring genetic alterations was observed across the 10 patients with presumed MET amplification (Table 2). The detected alterations are consistent with the previously described glioblastoma landscape [3].

Recent and ongoing trials of INC280 in lung cancer and hepatocellular carcinoma are exploring the predictive markers that are suggested by preclinical data. So far, MET exon 14 skipping mutations in lung cancer are emerging as the most robust predictive marker, and the clinical data suggest that both MET copy number and protein overexpression may have predictive value as well, but appropriate cut-offs still need to be established [10, 27, 28] MET exon 14 skipping mutations have also recently been reported in secondary glioblastoma with a frequency of $\sim 14 \%$, and at lower frequencies in primary glioblastoma and low-grade glioma [29]. In addition, PTPRZ1-MET fusions were found in secondary glioblastoma, where they can co-occur with MET exon 14 skipping mutations [7, 29]. PTPRZ1-MET and other MET fusions were also reported in pediatric glioblastoma [30]. Preclinical as well as emerging clinical data suggest that brain malignancies with MET mutations and/or fusions are responsive to MET inhibitors [29, 30]. Therefore, optimizing patient selection for investigation of INC280 in glioblastoma may require a more comprehensive characterization of MET molecular abnormalities beyond copy number. Another potential predictive biomarker that should be considered in future trials of MET inhibitors in glioblastoma is HGF expression by the tumor, based on preclinical data [12]. While there is good rationale for targeting MET in glioblastoma, our study illustrates the need for further molecular profiling to identify the subset of patients who may benefit.

INC280 has shown some degree of brain penetration in preclinical species (our unpublished observation), but the extent of brain exposure and MET inhibition in patients with glioblastomas are unknown and may also have affected outcome. Future trials on novel agents should study this systematically early on in the clinical trial program to ensure the target is reached.

To conclude, the combination INC280/buparlisib resulted in reduced exposure of both drugs and no clear signal of activity in recurrent PTEN-deficient glioblastoma. With the assay and cut-off for MET amplification used, no clear activity signal was seen with INC280 single-agent treatment. However, consideration of confounding factors and a more stringent molecular selection strategy could be used to further explore the role of MET inhibitors for the treatment of recurrent glioblastoma.

\section{Study limitations}

This study is limited by the lack of data available on the MET GCN cut-off number for molecular selection. We used $\leq 5$ as a cut-off based on limited emerging data from other capmatinib trials, and, due to the relatively small and potentially molecularly diverse patient population, we were unable to refine this copy number in the current study. This molecular-based therapy uses 'historical information' because all biopsies to determine MET status were archival, without accounting for the effects of intervening therapy or molecular drift. Thus, it is possible the molecular profile at study entry differed from that extrapolated from the analysis of archival tissue.

Acknowledgements This study (CINC280X2204) is funded by Novartis Institutes for Biomedical Research (China). The authors would like to acknowledge the assistance of all investigators, clinical 
trial staff, participants and past and present INC280 EPT members. The authors thank Paul Coyle, Vicki Betts, PhD, Jackie Johnson, PhD, and Gillian Brodie, MSc, of Novartis Ireland Ltd for providing medical writing support/editorial support, which was funded by Novartis Pharma AG, Basel, Switzerland in accordance with Good Publication Practice (GPP3) guidelines (https://www.ismpp.org/gpp3).

Funding This study is funded by Novartis Institutes for Biomedical Research (China). A.B. Lassman was supported in part by grants P30CA013696 and UG1CA189960 from the NCI.

\section{Compliance with ethical standards}

Conflicts of interest In relation to this presentation, we declare the following, real or perceived conflicts of interest: M. van den Bent has received grants from Abbvie, and honoraria from Cellgene, BMS, Boehringer, AGIOS and VaXIMM. A. Azaro has received consulting fees from Orion Pharmaceuticals and Amcure GmbH. F. De Vos has received financial support for conducting clinical trials from Novartis, BMS, AbbVie and Bioclin. J.M. Sepulveda has received consulting fees from Celgene, Pfizer and Abbvie; he has received research grants from Pfizer and Catalysis. W.K.A. Yung holds stocks in DNATrix; he has received honoraria from DNATrix and Boehringer Ingelheim; he holds patents, royalties and/or intellectual property in, and has participated in a consulting or advisory role for DNATrix; he has received travel and/or accommodation expenses from Boehringer Ingelheim. P. Wen has received grants/research support from Lilly USA, Agios, AstraZeneca, Beigene, Eli Lily, Immunocellular Therapeutics, Kazai, Kadmon, Karyopharm, Merck, Novartis, Oncoceutics, Vascular Biogenics and Vaccines; he has received speaker's bureau fees from Merck; he has received consultant/advisory board fees from Genentech/Roche, Taiho Oncology, Novartis, Agios Pharmaceuticals Inc, Merck, Puma, Abbvie, AstraZeneca, Eli Lilly, GW Pharmaceuticals, Immunomic Therapeutics, Kadmon, Vascular Biogenics, Ziopharm, Monteris and Tocagen. A. Lassman reports grants and non-financial support from Novartis, during the conduct of the study; personal fees and non-financial support from Orbus, grants, personal fees and nonfinancial support from Karyopharm, personal fees and non-financial support from NW Biotherapeutics, grants and non-financial support from Oncoceutics, personal fees and non-financial support from Agios, personal fees and non-financial support from Celgene, personal fees and non-financial support from Novocure, non-financial support from Tocagen, non-financial support from BMS, grants, personal fees and non-financial support from Kadmon, grants and non-financial support from Genentech/Roche, grants and non-financial support from Amgen, grants and non-financial support from Millenium, non-financial support from Celldex, grants and non-financial support from Pfizer, nonfinancial support from Keryx/Aeterna Zentaris, grants and non-financial support from VBI Vaccines, grants and non-financial support from Beigene, personal fees from Bioclinica as an expert blinded independent reviewer of clinical and imaging data for a BMS-sponsored trial, personal fees from prIME Oncology, personal fees and non-financial support from Sapience, personal fees from WebMD, personal fees and non-financial support from Physicians' Education Resource, personal fees from Cortice, grants, personal fees and non-financial support from AbbVie, personal fees and non-financial support from Forma, personal fees and non-financial support from Bayer, grants and non-financial support from Global Coalition for Adaptive Research, personal fees and non-financial support from American Society of Clinical Oncology, grants and non-financial support from QED, grants, personal fees and non-financial support from NCI, non-financial support from New York University, grants and non-financial support from NRG Oncology/RTOG-Foundations, grants from UCLA, grants from Northwestern University, grants from James S. McDonnell Foundation, non-financial support from Yale University, non-financial support from Radiological
Society of North America, non-financial support from FDA, personal fees from Italian Foundation for Cancer Research, personal fees and non-financial support from Abbott Molecular, and personal fees from Elsevier, outside the submitted work M. Joerger has received grants from BMS and AstraZeneca. G. Tabatabai has served on Advisory Boards for AbbVie and BMS, has received research/travel grants from Medac, Novocure and Roche Diagnostics, and has received speaker's fees from Meda and Novocure. J. Rodon reports non-financial support and reasonable reimbursement for travel from European Journal of Cancer, Vall d'Hebron Institut of Oncology, Chinese University of Hong Kong, SOLTI, Elsevier, GlaxoSmithKline; receiving consulting and travel fees from Novartis, Eli Lilly, Orion Pharmaceuticals, Servier Pharmaceuticals, Peptomyc, Merck Sharp \& Dohme, Kelun Pharmaceutical/Klus Pharma, Spectrum Pharmaceuticals Inc, Pfizer, Roche Pharmaceuticals, Ellipses Pharma (including serving on the scientific advisory board from 2015-present), receiving research funding from Bayer and Novartis, and serving as investigator in clinical trials with Spectrum Pharmaceuticals, Tocagen, Symphogen, BioAtla, Pfizer, GenMab, CytomX, Kelun-Biotech, Takeda-Millenium, GlaxoSmithKline, IPSEN and travel fees from ESMO, US Department of Defense, Louissiana State University, Hunstman Cancer Institute, Cancer Core Europe, Karolinska Cancer Institute and King Abdullah International Medical Research Center (KAIMRC). R. Tiedt, T. Kirsilae and S. Vicente are employees of Novartis Pharma AG. S. Zhao is an employee of Novartis Institutes for Biomedical Research (China). A. Balbin is an employee of Novartis Institutes for Biomedical Research (US). H. Zhang is an employee of Novartis and holds shares with Novartis. W. Wick receives study support to the institution from Apogenix, Pfizer and Roche.

Ethical approval The study protocol and all amendments were reviewed by the Independent Ethics Committee or Institutional Review Board for each center. All procedures performed in studies involving human participants were in accordance with the ethical standards of the institutional and/or national research committee and with the 1964 Helsinki declaration and its later amendments or comparable ethical standards.

Informed consent Informed consent was obtained from all individual participants or appropriate surrogates included in the study. Additional information on the study was provided verbally by the study investigator or in a written format.

Open Access This article is distributed under the terms of the Creative Commons Attribution 4.0 International License (http://creativeco mmons.org/licenses/by/4.0/), which permits unrestricted use, distribution, and reproduction in any medium, provided you give appropriate credit to the original author(s) and the source, provide a link to the Creative Commons license, and indicate if changes were made.

\section{References}

1. McFaline-Figueroa JR, Lee EQ (2018) Brain tumors. Am J Med 131(8):874-882

2. Stupp R, Mason WP, van den Bent MJ et al (2005) Radiotherapy plus concomitant and adjuvant temozolomide for glioblastoma. $\mathrm{N}$ Engl J Med. 352(10):987-996

3. Brennan CW, Verhaak RG, McKenna A, Campos B, Noushmehr H, Salama SR, Zheng S, Chakravarty D, Sanborn JZ, Berman SH, Beroukhim R et al (2013) The somatic genomic landscape of glioblastoma. Cell 155(2):462-477 
4. Tasaki T, Fujita M, Okuda T et al (2016) MET expressed in glioma stem cells is a potent therapeutic target for glioblastoma multiforme. Anticancer Res. 36(7):3571-3577

5. Malla R, Gopinath S, Alapati K et al (2010) Downregulation of uPAR and cathepsin $\mathrm{B}$ induces apoptosis via regulation of $\mathrm{Bcl}-2$ and $\mathrm{Bax}$ and inhibition of the PI3K/Akt pathway in gliomas. PLoS ONE 5(10):e13731

6. Abounader R, Lal B, Luddy $\mathrm{C}$ et al (2002) In vivo targeting of $\mathrm{SF} / \mathrm{HGF}$ and c-met expression via U1snRNA/ribozymes inhibits glioma growth and angiogenesis and promotes apoptosis. FASEB J 16(1):108-110

7. Bao ZS, Chen HM, Yang MY et al (2014) RNA-seq of 272 gliomas revealed a novel, recurrent PTPRZ1-MET fusion transcript in secondary glioblastomas. Genome Res 24(11):1765-1773

8. Wang SI, Puc J, Li J et al (1997) Somatic mutations of PTEN in glioblastoma multiforme. Cancer Res 57(19):4183-4186

9. Liu X, Wang Q, Yang G et al (2011) A novel kinase inhibitor, INCB28060, blocks c-MET-dependent signaling, neoplastic activities, and cross-talk with EGFR and HER-3. Clin Cancer Res 17(22):7127-7138

10. Schuler M, Berardi R, Lim WT et al (2016) Phase I study of the safety and efficacy of the cMET inhibitor capmatinib (INC280) in patients with advanced cMET + NSCLC. Paper presented at Multidisciplinary symposium on thoracic oncology, 22-24 September 2016, Chicago, IL

11. Wu YL, Zhang L, Kim DW et al (2018) Phase Ib/II study of capmatinib (INC280) Plus gefitinib after failure of epidermal growth factor receptor (EGFR) inhibitor therapy in patients with EGFRmutated, MET factor-dysregulated non-small-cell lung cancer. J Clin Oncol 36(31):3101-3109

12. Baltschukat S, Schacher Engstler B, Huang A et al (2019) Capmatinib (INC280) Is active against models of non-small cell lung cancer and other cancer types with defined mechanisms of MET activation. Clin Cancer Res 25(10):3164-3175

13. Matas-Cespedes A, Rodriguez V, Kalko SG et al (2014) Disruption of follicular dendritic cells-follicular lymphoma cross-talk by the pan-PI3K inhibitor BKM120 (Buparlisib). Clin Cancer Res 20(13):3458-3471

14. Netland IA, Forde HE, Sleire L et al (2016) Treatment with the PI3K inhibitor buparlisib (NVP-BKM120) suppresses the growth of established patient-derived GBM xenografts and prolongs survival in nude rats. J Neurooncol 129(1):57-66

15. Wen PY, Touat M, Alexander BM et al (2019) Buparlisib in patients with recurrent glioblastoma harboring phosphatidylinositol 3-kinase pathway activation: an Open-Label, Multicenter, Multi-Arm Phase II Trial. J Clin Oncol 37(9):741-750

16. Ando Y, Inada-Inoue M, Mitsuma A et al (2014) Phase I doseescalation study of buparlisib (BKM120), an oral pan-class I PI3K inhibitor, in Japanese patients with advanced solid tumors. Cancer Sci 105(3):347-353

17. Bendell JC, Rodon J, Burris HA et al (2012) Phase I, dose-escalation study of BKM120, an oral pan-Class I PI3K inhibitor, in patients with advanced solid tumors. J Clin Oncol 30(3):282-290

18. Wen PY, Macdonald DR, Reardon DA et al (2010) Updated response assessment criteria for high-grade gliomas: response assessment in neuro-oncology working group. J Clin Oncol 28(11):1963-1972
19. Kim B, Myung JK, Seo JH et al (2010) The clinicopathologic values of the molecules associated with the main pathogenesis of the glioblastoma. J Neurol Sci 294(1-2):112-118

20. Vansteenkiste JF, Canon JL, De Braud F et al (2015) Safety and efficacy of buparlisib (BKM120) in patients with PI3K pathwayactivated non-small cell lung Cancer: results from the Phase II BASALT-1 Study. J Thorac Oncol 10(9):1319-1327

21. Tanwandee T, Sukeepaisarnjaroen W, Lam Chan S et al (2016) A phase (Ph) II study of the efficacy and safety of the cMET inhibitor capmatinib (INC280) in patients (pts) with advanced hepatocellular carcinoma (HCC). Paper presented at Journal of Clinical Oncology

22. Wolf J (2018) Results of the GEOMETRY mono-1 phase II study for evaluation of the MET inhibitor capmatinib (INC280) in patients with MET exon-14 skipping mutated advanced non-small cell lung cancer. Abstract \#LBA52. Paper presented at: European Society of Medical Oncology (ESMO), 19-23 October 2018, Munich, Germany

23. Kotani H, Ebi H, Kitai H et al (2016) Co-active receptor tyrosine kinases mitigate the effect of FGFR inhibitors in FGFR1-amplified lung cancers with low FGFR1 protein expression. Oncogene 35(27):3587-3597

24. Ilie MI, Bence C, Hofman V et al (2015) Discrepancies between FISH and immunohistochemistry for assessment of the ALK status are associated with ALK 'borderline'-positive rearrangements or a high copy number: a potential major issue for anti-ALK therapeutic strategies. Ann Oncol 26(1):238-244

25. Yan B, Yau EX, Bte Omar SS et al (2010) A study of HER2 gene amplification and protein expression in gastric cancer. J Clin Pathol 63(9):839-842

26. Cabillic F, Gros A, Dugay F et al (2014) Parallel FISH and immunohistochemical studies of ALK status in 3244 non-small-cell lung cancers reveal major discordances. J Thorac Oncol 9(3):295-306

27. Bang YJ et al (2014) Phase I study of the safety and efficacy of INC280 in patients with advanced MET-dependent solid tumours. Abstract 25202014

28. Wolf J, Seto T, Han J-T et al (2018) Results of the GEOMETRY mono-1 phase II study for evaluation of the MET inhibitor capmatinib (INC280) in patients (pts) with MET ex14 mutated advanced nonsmall cell lung cancer (NSCLC). Paper presented at ESMO2018

29. $\mathrm{Hu} \mathrm{H}, \mathrm{Mu} \mathrm{Q}, \mathrm{Bao} \mathrm{Z}$ et al (2018) Mutational landscape of secondary glioblastoma guides MET-targeted trial in brain tumor. Cell 175(6):1665-1678.e18

30. International Cancer Genome Consortium PedBrain Tumor Project (2016) Recurrent MET fusion genes represent a drug target in pediatric glioblastoma. Nat Med 22(11):1314-1320

31. Frampton GM, Fichtenholtz A, Otto GA et al (2013) Development and validation of a clinical cancer genomic profiling test based on massively parallel DNA sequencing. Nat Biotechnol 31(11):1023-1031

Publisher's Note Springer Nature remains neutral with regard to jurisdictional claims in published maps and institutional affiliations. 


\section{Affiliations}

\section{Martin van den Bent ${ }^{1}(1)$. Analia Azaro ${ }^{2}$. Filip De Vos $^{3}$. Juan Sepulveda ${ }^{4} \cdot$ W. K. Alfred Yung ${ }^{5}$. Patrick Y. Wen ${ }^{6}$. Andrew B. Lassman ${ }^{7} \cdot$ Markus Joerger $^{8}$. Ghazaleh Tabatabai ${ }^{9} \cdot$ Jordi Rodon $^{5} \cdot$ Ralph Tiedt $^{10}$ - Sylvia Zhao ${ }^{11}$. Tiina Kirsilae $^{10} \cdot$ Yi Cheng $^{11} \cdot$ Sergio Vicente ${ }^{10} \cdot$ O. Alejandro Balbin ${ }^{12} \cdot$ Hefei Zhang ${ }^{11} \cdot$ Wolfgang Wick $^{13}$}

1 Erasmus University Medical Center (MC) Cancer Institute, Rotterdam, The Netherlands

2 Molecular Therapeutics Research Unit (UITM), Department of Medical Oncology, Vall d'Hebron University Hospital, Barcelona, Spain

3 University Medical Center Utrecht, Utrecht, The Netherlands

4 Hospital Universitario, 12 de Octubre, Madrid, Spain

5 MD Anderson Cancer Center, Houston, TX, USA

6 Center for Neuro-Oncology, Dana-Farber Cancer Institute and Harvard Medical School, Boston, MA, USA

7 Department of Neurology and Herbert Irving Comprehensive Cancer Center, Columbia University Irving Medical Center, New York, NY, USA

8 Cantonal Hospital, St. Gallen, Switzerland

9 Interdisciplinary Division of Neuro-Oncology, Center for CNS Tumors, Comprehensive Cancer Center, University
Hospital Tübingen, Hertie Institute for Clinical Brain Research \& Eberhard Karls University Tübingen, German Cancer Consortium (DKTK), DKFZ Partner Site Tübingen, Tübingen, Germany

10 Novartis Pharma AG, Basel, Switzerland

11 Novartis Institutes for Biomedical Research (China), Shanghai, China

12 Novartis Institutes for Biomedical Research (United States), Boston, MA, USA

13 Clinical Cooperation Unit Neurooncology, German Cancer Consortium (DKTK), German Cancer Research Center (DKFZ), and Neurology Clinic and National Center for Tumor Diseases, University Hospital Heidelberg, Heidelberg, Germany 